\title{
Diagnosis of Gastritis - Review from Early Pathological Evaluation to Present Day Management
}

\author{
Imre Laszlo Szabo, Kata Cseko, Jozsef Czimmer and \\ Gyula Mozsik
}

Additional information is available at the end of the chapter

http://dx.doi.org/10.5772/52884

\section{Introduction}

The gastritis is an inflammatory condition of the gastric mucosa characterized by existence of elementary histological alternations. However these structural changes observed by the pioneer of gastric histology were noted more than a century ago, their etiology and proper interpretation for clinical practice required much longer time.

The ancient Egyptians wrote that the diseases of internal organs are difficult to detect even in well-preserved bodies, hence they were not able to comprehend outstanding discoveries on the stomach as they did on other organ diseases. The first major discovery in the field of gastric diseases was the description of gastric cancer by the Persian Avicenna around 1000 (quoted by Rugge et al, 2003). At the same time the discoveries of non-neoplastic gastric diseases, especially gastritis, was really elusive for quite a long time due to less macroscopic features and to post-mortem alternations. The inflammation of the inner lining of the stomach was first noted as "gastritis" by a German physician, Georg Ernst Stahl in 1728 (quoted by Bock, 1974). Italian anatomical pathologist Giovanni Battista Morgagni further described the signs of gastric inflammation. He gave the first classical description of an erosive or ulcerating gastritis. He stated that some of the erosions can become gangrenous, and described corrosive gastritis as it was the most well-known gastritis form of that time due high number of lye intoxication. French physician, François-Joseph-Victor Broussais gathering information by autopsy of dead French soldiers between 1808 and 1831, described common chronic gastritis as he called "Gastritides", and sometimes got delusive conclusions as gastritis was the cause of ascites and other diseases, like typhoid fever and meningitis (Bock, 1974). Jones Handfield and Wilson Fox (1854) described microscopic changes of mucous membrane in gastric inflammation, which exists in diffuse and segmental forms. Not much 
later another British physician, William Brinton (1859) emphasized the symptomatic and microscopic differences of acut, subacute and chronic gastritis in his medical book entitled "Diseases of Stomach", and described haemorrhagic erosion and follicular ulceration. Meanwhile Baron Carl von Rokitansky besides his major discoveries was the first to note hypertrophic gastritis in 1855. The next major footstep was done by Samuel Fenwick in 1870, who noted the presence of glandular atrophy due to gastric inflammation when classifying gastric lesions and anatomical alternations of the gastric mucosa (Fenwick, 1870). He also discovered that pernicious anaemia is associated with gastric mucosal atrophy. German surgeon, Georg Ernst Konjetzny using surgical specimens showed first that both gastric ulcer and gastric cancer are either secondary diseases or are associated in their pathogenesis to chronic gastric inflammation. Shields Warren and Willam A. Meissner described intestinal metaplasia of the stomach. They noted intestinal metaplasia as a feature of chronic gastritis, and found seldom extensive in duodenal ulcer patients, while it was extensive in stomachs removed due to carcinoma (Warren \& Meissner, 1944; Rugge et al, 2003).

\section{In vivo diagnosis of gastritis - Introduction of gastroscopy}

In vivo diagnosis of gastritis got a huge drive with the development of routine gastroscopy. By the 1950's, Rudolf Schindler's part-flexible endoscopes became very common making rigid endoscopes to disappear. From 1960's, the commercial introduction of flexible endoscopes gave easy access for gastric biopsy and diagnosis of gastritis (Palmer, 1956). By the use of biopsy based histology Schindler gave overview of gastritis in his monograph entitled 'Gastritis' in 1947, he divided inflammation into 'superficial', 'atrophic' and 'hypertrophic' gastritis chronica (Schindler, 1947). Cheli and Dobero in 1958 differentiated 'superficial', 'interstitial' and 'atrophic gastritis' in the terminology of gastric inflammatory lesions (Cheli \& Dobero, 1956). Up to his time classifications lack topography, but in 1972, Whitehead distinguished antral, fonical, corporal and pyloric region inflammation based on classical pathomorphology. Whitehead divided chronic gastritis into 'superficial' and 'atrophic', both 'active' or 'in-active' based on the presence of granulocyte infiltration in epithelium and interstitium beside the inflammatory infiltration of lamina propria from lymphocytes and plasmatic cells (Whitehead et al, 1972). He suggested the use of a mild-moderate-severe scale to evaluate the atrophy. He also introduced the evaluation of intestinal and pseudopyloric metaplasia into everyday pathological assessment.

Based on recent research data, Robert G. Strickland and Ian R. MacKay proposed the classification of gastritis based on additional factors just beside just histology and topography (Strickland \& Mackay, 1973). They suggested that immunological and etiological data should be included along with pathomorphological and topographic parameters; gastric parietal cell antibody and serum level of gastrin have to be seen to get better classification of chronic gastritis. They used the term 'Type A gastritis' for gastric corporal inflammation mostly corresponding to pernicious anaemia, and 'Type B' for antral gastritis suspected to be induced by duodeno-gastric reflux according to some thoughts. In 1975 George B Jerzy Glass and Capecomorin S. Pitchumoni added the 'Type AB' to the classification. This term 
was aimed to be used for extended gastritis observed in corpus to pre-pyloric region (Glass \& Pitchumoni, 1975). Those cases were named 'AB-plus' where antibody positivity was also founds against parietal cells. In 1980, the classification was further modified by Correa dividing chronic gastritis into autoimmune chronic gastritis with pernicious anaemia, 'hypersecretory' and 'environmental' forms. He described the gastritis accompanying ulcer to hypersecretory. All the rest of gastritis was called environmental, which are mostly due to diet and geographic localization (Correa, 1980). Later as more data were known from histological assessments, he changed his classification for 'diffuse antral', 'diffuse corporal' and 'multifocal' gastritis. By seeing his nomenclature, sometimes showing etiology, sometimes reflecting topography, we are able to see the controversy existed between pathologist and clinicians in the field of gastritis at that time. The extensiveness in topography along with histological and etiologic features were not to be combined in an uniformed nomenclature, even Correa in 1988 returned to his previous version of classification (Correa, 1988). Later, he went to different direction by dividing gastritis into two major categories of 'atrophic' and 'non-atrophic' gastritis.

The next major step was added by Judith I. Wyatt and Michael F. Dixon by the introduction of 'type C' gastritis for chemical (drug)-induced inflammation of gastric mucosa (Wyatt \& Dixon, 1988). Two years later, examining 316 patients Sobala confirmed that most of reflux gastritis in intact (non-operated) stomach is not due to bile reflux but rather NSAID use. According to their proposition the term 'type $C^{\prime}$ or 'chemical' gastritis might be used for condition caused by both etiology (Sobala et al, 1990).

\section{Modern time - Development of the Sydney system}

Modern aspects of gastritis classification and knowledge of its biological course and consequences were relatively well-known at the time when Helicobacter pylori (H. pylori) was discovered by Robin Warren and Barry Marshall in 1982 (Warren \& Marshall, 1983). Their discovery showed that the commonest form of gastritis is simply an infectious disease caused by an otherwise known pathogen. At that time gastroenterologist and pathologist had limited knowledge on even simple aspects of this chronic bacterial inflammation of gastric mucosa and the classification system used was confusing and differing from county to another. Very soon considerable amount of data became known about H. pylori, its disease associations and their natural courses by many physicians, microbiologist and basic researchers entering the field. As a consequence in the late 1980's several pre-meeting of Working Party (Anthony Axon, Wladimir Bogomoletz, Michael F. Dixon, Steart Goodwin, Jules Haot, Konrad L. Heilmann, Adrian Lee, Barry Marshall, George Misiewicz, Ashley Price, Penti Sipponen, Enrico Solcia, Manfred Stolte, Robert Strickland, Guido Tytgat) was set up to review the biology and natural course of chronic gastritis and to propose a new classification for gastritis by the leadership of George Misiewicz and Guido Tytgat. The working party actually consisted of two groups mainly working parallel to another: as a pathological group and a clinical group (Sipponen \& Price, 2011). Based on new etiological facts and data collected, a new system of classification was presented at the World Congress 
of Gastroenterology held in Sydney, Australia in 1990, and subsequently published as six papers in the Journal Gastroenterology and Hepatology. The existence of the two Working Parties reflects on the histological and endoscopic division of Sydney System. The histological division of Sydney System intended to be a practical guideline showing which of the morphological features of gastritis in endoscopic biopsy specimens should be documented (Price, 1991). Type, severity and extent of gastric inflammation linked to possible etiology should be detailed according to a chart designed (see Fig. 1). The Sydney System declared the routine biopsy sampling protocol, the number of biopsies should be taken, the biopsies' proper localisation (two from antrum and two from corpus, both from anterior and posterior walls) and sample fixation in adequately labelled separate containers (Misiewicz et al, 1990; Price \& Misiewicz, 1991). Many pathologist think to these last as the most important conclusions of the system. The system also established a four-level scale for defining severity (extent) of pathomorphological elements.

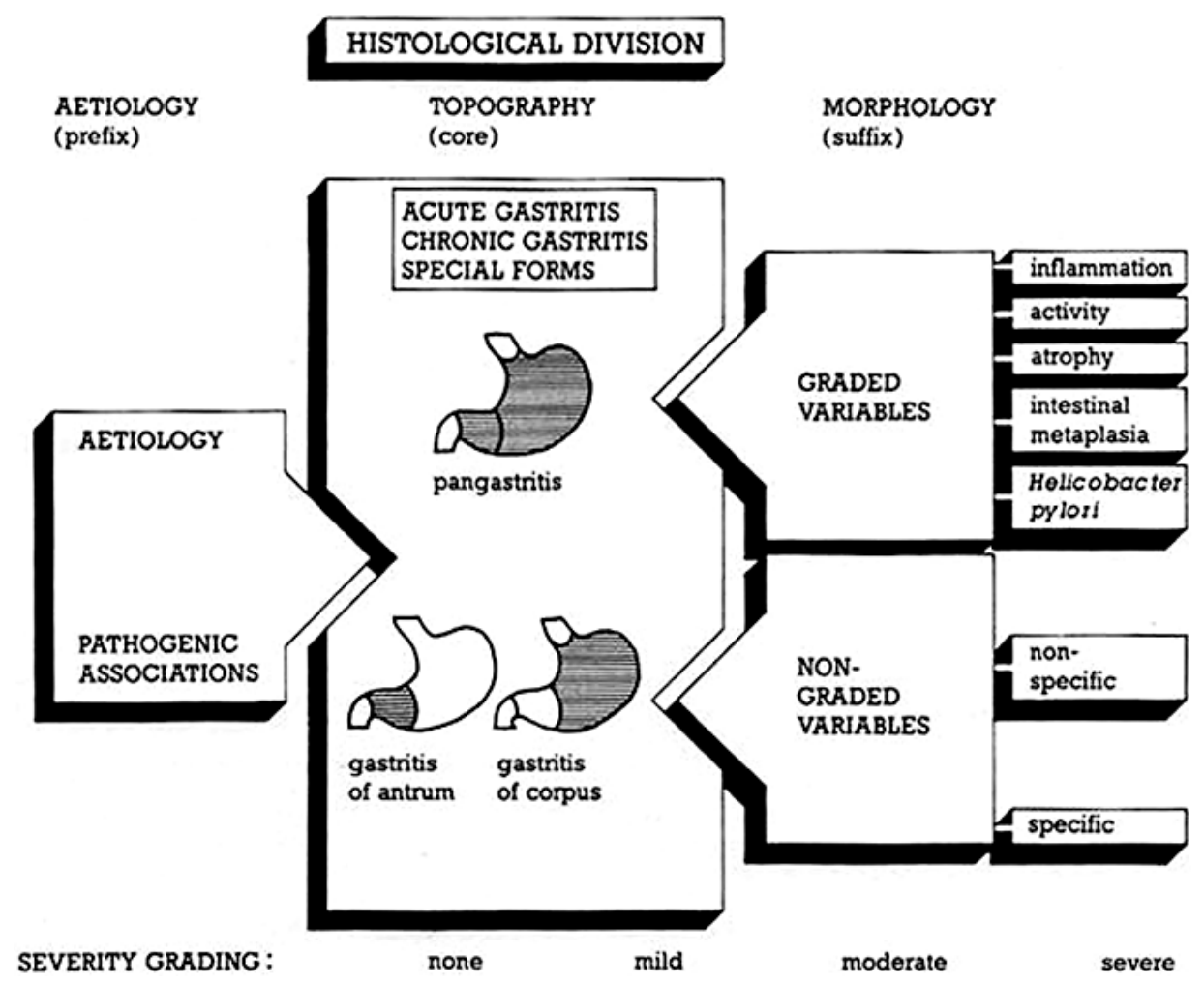

Figure 1. Chart designed for the histological division of the original Sydney System as presented to the World Congress of Gastroenterology. Published in Journal of Gastroenterology and Hepatology in 1991. Describes the nomenclature should be used in histological reporting of gastritis. Adopted etiological suffix phrases to topography and morphological features with grading suffixes to be documented in endoscopic biopsy reporting. 


\begin{tabular}{|c|c|c|}
\hline Year & Author/Classification & Comment \\
\hline$\overline{1728}$ & Stahl & 'Gastritis' defined (quoted by Bock, 1974) \\
\hline 1771 & Morgagni & 'Erosive' and 'ulcerating gastritis" described (Crawford et al, 1932) \\
\hline 1859 & William Brinton & Acute, subacute and chronic gastritis differentiated $\square$ \\
\hline 1855 & Rokitansky & Hypertrophic gastritis described (quoted by Vaugham, 1945). \\
\hline 1870 & Fenwik & Gastric atrophy described $\square$ \\
\hline 1944 & Warren \& Meissner & Intestinal metaplasia described $\square$ \\
\hline 1947 & Wood & First gastric biopsy, 'Gastritis' defined (Wood et al, 1949) \\
\hline 1956 & Cheli \& Dobero $x$ & Superficial, Interstitial and Atrophic gastritis $\square$ \\
\hline 1956 & Eder-Palmer $\nabla$ & Introduction of flexible fibre optic endoscope (Palmer, 1956) \\
\hline 1972 & Whitehead $x$ & $\begin{array}{l}\text { Superficial, Atrophic, both 'Active' or 'In-active'. Type and Stage of } \\
\text { activity. Presence and type of metaplasia } \square\end{array}$ \\
\hline 1973 & Strickland \& MacKay $\propto$ & $\begin{array}{l}\text { A (autoimmune) PCA+ in 95\% and IFA+ in 75\%, B (nonautoimmune }= \\
\text { environmental) } \square\end{array}$ \\
\hline 1975 & Pitchumoni $\ltimes$ & $\begin{array}{l}\text { A (autoimmune-corpus), B (antrum), AB (both antrum and corpus) } \\
\text { PCA+ or - (Glass \& Pitchumoni, 1975) }\end{array}$ \\
\hline 1980 & Correa $x$ & Autoimmune, Hypersecretory, Environmental $\square$ \\
\hline 1988 & Correa $x$ & $\begin{array}{l}\text { Diffuse corporal (autoimmune), Chr. diffuse antral, Multifocal } \\
\text { environmental, Chr. Superficial, Lymphocytic, Postgastrectomy } \square\end{array}$ \\
\hline 1989 & Owen $x$ & Chr. non-specific type A, Chr. non-specific type B $\square$ \\
\hline 1990 & Yardley $x$ & $\begin{array}{l}\text { H. pylori gastritis, Metaplastic atrophic (type A, autoimmune), } \\
\text { Metaplastic atrophic (type B), Lymphocytic, Chemical } \square\end{array}$ \\
\hline 1990 & Dixon $x$ & 'Type C' proposed to reactive gastric lesions $\square$ \\
\hline 1990 & Sobala & Reflux gastritis defined as type $C$ gastritis $\square$ \\
\hline 1990 & Sydney $x$ & $\begin{array}{l}\text { Nonatrophic, Atrophic (Autoimmune, Multifocal), Special forms. Four- } \\
\text { level scale, proper biopsy sampling \& handling, standard reporting } \\
\text { aiming etiology (Misiewicz et al, 1990) }\end{array}$ \\
\hline 1994 & Appelman $x$ & $\begin{array}{l}\text { Acute or Chronic; Helicobacter type, Atrophic (type A, type B), } \\
\text { Lymphocytic, Focal \& miscellaneous, Chemical gastropathies }\end{array}$ \\
\hline 1996 & Up-dated Sydney $x$ & $\begin{array}{l}\text { Biopsy location changed from anterior and posterior wall to greater } \\
\text { and lesser curvature (Dixon et al, 1996) }\end{array}$ \\
\hline 2000 & Padova $\not$ & Classification of dysplasia and related lesions (Rugge et al, 2000) \\
\hline 2005 & OLGA $x$ & Classification of grading mucosal atrophy (Rugge et al, 2005b) \\
\hline
\end{tabular}

○ Classification (system) $\nabla$ Manufacturer $\square$ See ref. under same name and year

Table 1. History of Classification of Gastritis.

The Sydney System which actually allowed statements to be made on etiology, topography and morphology of gastritis for the first time, was not accepted everywhere immediately, especially in the United States. The main criticism was that the some of the commonly used descriptive names were not enabled into the system, like the 'multifocal atrophic gastritis' or 'diffuse antral gastritis'. Although, by that time it was already accepted that the Sydney Sys- 
tem was not designed to be the textbook of gastric pathology, but to be a guide for standard methology of reporting. Correa and Yardley criticized the system for missing out certain types of the gastritis and well as it is not a 'classification' (Correa \& Yardley, 1992). Consequently, a new system needed to gain wider acceptance.

In 1994, a two-day consensus meeting was held in Houston. After this another consensus report, "Up-dated Sydney System" was published in 1997 (Dixon et al, 1996). Original classification of gastritis dividing into acute, chronic and special forms, and grading of chronic inflammation, polymorph activity, atrophy, intestinal metaplasia and H. pylori density into mild, moderate and marked categories were kept. This up-dated system introduced a visual analogue scale for evaluating the severity of histopathological elements (grading). It changed the routine of endoscopic biopsy sampling by the introduction of biopsy sampling from the incisura angularis and modified corpus and antrum biopsy locations from the two opposite walls to lesser and greater curvature of both parts. The Up-dated Sydney Classification received different reactions among pathologists. Most of the pathologist agreed with the need of incisural biopsy, since the most degree of atrophy and intestinal metaplasia is found in the incisural region. That would reduce the sampling error of missing premalignant lesions and improve the diagnosis of multifocal gastritis. However, later prospective studies could not really show its benefit (Stolte \& Meining, 2001). Even in our conducted study higher number of intestinal metaplasia were found in antral biopsies then in the biopsies taken from the incisura angularis (Szabo et al, 2012). After the development of the visual analogue scale according to the Up-dated Sydney System, the grading of atrophy still continued to show a considerable inter-observer variability (El-Zimaity et al, 1996). The updated system categorised chronic gastritis into 'non-atrophic' and 'atrophic' forms with the latter divided into autoimmune (diffuse corpus atrophy) and multifocal. Histological reporting of gastritis should take into account the topographical pattern (antral or corpus predominant), and the final diagnostic term should ideally combine morphology and etiology to maximize the clinical value of gastric biopsy diagnosis (Dixon et al, 1997). The up-dated system beside its major benefits in further standardizing endoscopic sampling, histological assessment and formality of reporting, still showed weaknesses specially in grading atrophy as pointed out by Johan A. Offerhaus in 1999 (see ref). His proposition was to simplify the grading system to two grades (low and high).

\section{Classification by Appleman}

The clearest division of gastritis for clinicians was published by Appleman in 1994. He divided gastric inflammatory diseases to acute and chronic (see Table II). The most common form of gastritis that was called earlier as chronic diffuse antral gastritis, gastritis chronic type $\mathrm{B}$, gastritis chronica active antralis, gastritis non-specifica or gastritis typus hypersecretions was named as Helicobacter pylori related gastritis. At this time lot of work proved that $H$. pylori infection causes chronic gastritis in the prepyloric region later leading to atrophy of glands and development of gastric adenocarcinoma and less frequently of lymphoma (Appelman, 1994, Kozlowski et al, 2011). 
According to Appelman's classification the autoimmune gastritis used to be called as gastritis autoimmunogenes, gastritis chronic atrophica typus A, gastritis chronic typus A and gastritis chronic diffusa corporis, was called to autoimmune chronic atrophic gastritis. Appelman pointed out the presence of autoantibodies against parietal cells and intrinsic factor being important in diagnosis, enterochromaffinlike (ECL) cell hyperplasia and risk of carcinoma.

Appelman's classification of gastritis continues with the multifocal atrophic gastritis earlier called as environmental gastritis or type B chronic atrophic gastritis. At that time the cause of this form of gastritis was not clearly known. Beside known environmental factors responsible for geographic differences in its epidemiology, raising circumstantial evidences from an Italian study examining gastric distribution of $H$. pylori, pointed out the role of $H$. pylori in its generation (Rugge et al, 1993). Evidences suggested that H. pylori first infects the antrum, and later it involves the body leading to atrophic gastritis.

Appelman seeing similarity of the histological changes of patients with gastroenteric anastomosis and taking nonsteroidal anti-inflammatory (NSAID) medications, called third division of gastritis caused by bile reflux or NSAIDs to chemical gastropathies. Due to less inflammation these histological changes consisting foveolar hyperplasia, decrease of mucin in foveolar cells, superficial oedema, increase of smooth muscle fibres in the lamina propria were named as 'gastropathies'. Recognition of this distinction of gastritis greatly helped to simply classification, although many times elements histological changes usually found in chemical gastropathy can be noticed in other forms of gastritis as well as in other gastric disease. Finding them singular and unassociated wit other changes like atrophy, intestinal metaplasia, presence of bacteria, ulcers, polyps, should raise the possibility of chemical gastritis.

Appelman kept the name of lymphotic gastritis used by his frontiers for the fourth distinctive form of gastritis (Haot et al, 1988, 1990). In this form of chronic gastritis huge lymphocytic infiltration of the surface epithelium, superficial pits and lamina propria can be observed. Others used to call this as superficial gastritis, gastritis chronic erosive or gastritis varioliformis. That time in 1990, the histological changes seen in lymphocytic gastritis was already described in patients with sprues and gluten-sensitivity. Lymphocytic gastritis tends to form "varioliform gastritis" endoscopically. This includes thick folds and small bumps with central depression seen during endoscopy. But lymphocytic gastritis also can form giant folds leading clinical symptoms (Ménétrier's disease).

Appelman's division of gastritis contained a miscellaneous group of gastritis. There are many gastritis forms that do not differ significantly from similar inflammations found other organs, including those that occur in syphilis, mycobacterial and cytomegalovirus, human immunodeficiency virus infections, histoplasmosis, candidiasis, cryptosporidiosis and other opportunistic fungi. There is a family of granulomatous reactions or granulomatous gastritis. Some of these are part of a systemic or focal gut granulomatous disease, such as sarcoidosis or Crohn's disease, and some have been described as part of a systemic vasculitis syndrome or Whipple's disease. There are still others which are not associated with any other diseases and designated as 'isolated granulomatous gastritis'. Allergic gastritis is usually part of a gastrointestinal allergic disease. Appelman also categorized the recently described collagenous gastritis into this miscellaneous group. 


\begin{tabular}{|c|c|c|}
\hline \multirow[t]{3}{*}{ Acute } & \multicolumn{2}{|r|}{ Acute infectious gastritis (including $\mathrm{Hp}$ ) } \\
\hline & \multicolumn{2}{|r|}{ Erosive (caused mostly by NSAID or alcohol) } \\
\hline & \multicolumn{2}{|c|}{ Necrotising and haemorrhagic (caused mostly by ischaemia) } \\
\hline \multirow[t]{11}{*}{ Chronic } & \multicolumn{2}{|r|}{ Helicobacter pylori type } \\
\hline & \multirow[t]{2}{*}{ Atrophic } & Type A: autoimmune, diffuse \\
\hline & & Type B: non-autoimmune, multifocal, enviromental \\
\hline & Lymphocytic & Including varioliform, 'sprue-like' and Ménétrier-like \\
\hline & \multirow[t]{3}{*}{ Chemical $₫$} & Bile reflux \\
\hline & & NSAIDS \\
\hline & & others (caused by other damaging agents and physical trauma) \\
\hline & \multirow[t]{4}{*}{ Miscellaneous } & $\begin{array}{c}\text { Granulomatous (part of Crohn's, Whipple's, vasculitis, sarcoidosis or } \\
\text { isolated granulomatous gastritis) }\end{array}$ \\
\hline & & Allergic \\
\hline & & $\begin{array}{l}\text { Specific infectious (HIV, mycobacterial, syphilis, Cytomegalovirus, } \\
\text { histoplasmosis, cryptosporidiosis }\end{array}$ \\
\hline & & Collagenous \\
\hline
\end{tabular}

- Gastropathies

Table 2. Appleman's classification of gastritis (1994)

\section{Precancerous lesions}

Warren and Meissner describing intestinal metaplasia and recognising the clinical-pathological pattern of gastritis, described the bases of etiopathogenic relationship between gastric cancer and chronic gastritis (Warren \& Meissner, 1944; Rugge et al, 2003). In 1980, Morson et al. (see ref.) defined gastric precancerous conditions as atrophic gastritis, gastric ulcer, pernicious anaemia, gastric stumps, gastric polyps, and Ménétrier's disease. They emphasized that epithelial dysplasia being a precancerous lesion is common in these conditions; dysplasia should be graded as mild, moderate and severe; and underlined the problems of differentiating inflammatory or regenerative changes from mild dysplasia, and intramucosal carcinoma from severe dysplasia (Morson et al, 1980). Japanese pathologists by studying serial sections of gastric mucosa obtained from gastric cancer patients described several border line lesions with histological and cytological changes. The premalignant significance of these was questioned for quite a long time; finally, the long-term follow-up studies closed this debate (Rugge et al, 1994, 1997). The high inter-observer inconsistency in histological assessment of premalignant lesions and new result supporting their neoplastic intraglandular nature obtained from genotyping studies highlighted the need of a broad consensus to re- 
define precancerous lesions uniformly. International group of pathologists met in Padova, Italy in April, 1998 on an international consensus conference. The conference reached an agreement on the definitions of the spectrum of gastric premalignant lesions and on common glossary for pathologist and clinicians, and applied strict diagnostic criteria (Rugge et al, 2000) (see Table III).

\begin{tabular}{|c|c|c|c|}
\hline \multirow[t]{4}{*}{ Negative for dysplasia } & \multicolumn{3}{|c|}{ 1.0 Normal } \\
\hline & \multicolumn{3}{|c|}{ 1.1 Reactive foveolar hyperplasia } \\
\hline & \multirow{2}{*}{\multicolumn{2}{|c|}{1.2 Intestinal metaplasia }} & 1.2.1 Complete type \\
\hline & & & 1.2.2 Incomplete type \\
\hline \multirow[t]{2}{*}{ Indefinite for dysplasia } & \multicolumn{3}{|c|}{ 2.1 Foveolar hyperproliferation } \\
\hline & \multicolumn{3}{|c|}{ 2.2 Hyperproliferative intestinal metaplasia } \\
\hline \multirow{3}{*}{$\begin{array}{l}\text { Non-invasive neoplasma } \\
\text { (flat or elevated) }\end{array}$} & \multicolumn{3}{|c|}{ 3.1 Low-grade } \\
\hline & \multirow[t]{2}{*}{3.2 High-grade } & \multicolumn{2}{|c|}{$\begin{array}{l}\text { 3.2.1 Including suspicious for carcinoma without invasion } \\
\text { (intraglandular) }\end{array}$} \\
\hline & & \multicolumn{2}{|c|}{ 3.2.2 Including carcinoma without invasion (intraglandular) } \\
\hline \multicolumn{4}{|c|}{ Suspicious for invasive carcinoma } \\
\hline \multicolumn{4}{|c|}{ Invasive carcinoma } \\
\hline
\end{tabular}

Table 3. Padova Classification of gastric dysplasia and related lesions (2000)

\section{Evaluation of atrophy}

The Sydney System and Up-dated Sydney System attempted to incorporate etiologic, topographic, and morphologic criteria into a clinically relevant scheme to reach a broad consensus in classification of gastritis. One of the most controversial issues at the Houston Workshop was the concept of atrophy. It was pointed out that "normal" was not precisely defined; the loss of appropriate glands occurs with distinct patterns and has different functional significance in antrum and corpus; the relationship between atrophy and intestinal metaplasia remained incompletely understood; and the topographic patterns of distribution and its evolution made the atrophic gastritis to the most controversial topic of gastritis (Genta, 1996). Later long-term follow-up studies have confirmed that the extent of gastric mucosal atrophy parallels gastric cancer risk (Meining et al, 2002; Sipponen et al, 1985, 1994, 1997; Stolte et al, 2000). At the same time Sydney System did not present a reporting terminology for chronic gastritis understandable and providing prognostic and therapeutic information for clinicians. Whereas, hepatitis staging had already improved useful, simple terminology for interdisciplinary communication representing disease progression and cancer risk. 
Inspired by these facts, international group of gastroenterologists and pathologists named as Operative Link on Gastritis Assessment (OLGA) developed an improved histological staging system for gastric atrophy (Rugge \& Genta, 2005a, 2005b). OLGA system uses the gastric biopsy sampling protocol defined by Sydney System and the visual analogue system recommended by the Up-dated Sydney System. The gastritis staging is defined from combined extent of atrophy scored histologically with the topography of atrophy identified through biopsy mapping (see Fig. 2). Long-term follow-up studies proved that gastritis OLGA staging conveys relevant information on clinic-pathological outcome of gastritis and therefore $H$. pylori negative patients with low OLGA stages could be confidently excluded from secondary preventive surveillance invasive procedures (Rugge et al, 2010). Whereas patients with high OLGA stages (Stages III and IV) should be considered definitely candidates for endoscopic surveillance. Significant correlation was shown between OLGA stages and pepsinogen serology (marker of gastric atrophy). The ratio of pepsinogen I and II gives adequate information on the severity of atrophy, but its measurement fails to differentiate between neoplastic and non-neoplastic disease among patients with high stages of gastric mucosal atrophy (Rugge et al, 2010).

Similar to the OLGA system another system, called the Baylor system was also introduced. The Baylor system follows the Baylor biopsy protocol (which uses Sydney System biopsy sites with two additional distal corporal biopsies) and scores the atrophy of antrum and corpus independently (Graham et al, 2006). Antral atrophy stage is an average score, but corpus atrophy stage is independent of antral atrophy, independent of individual reading in each biopsy but dependent on location. As corpus atrophy starts at the incisura and extends in continuity proximally and towards the greater curve, atrophy in a distal biopsy is early and atrophy in the most proximal location is advanced. The comparison of the two atrophy grading systems is still controversial. Although there were studies performed showing the superiority of Baylor system over OLGA in indentifying cancer risk (El-Zimaity et al, 2008), the evaluation of gastric atrophy by OLGA is more widely used, further developed and more studied.

Rugge et al. developed the OLGIM system for more precise evaluation of cancer risk. This system basically incorporates the OLGA frame, but replaces the atrophy score with an assessment of intestinal metaplasia (IM) alone. Examining a series of more than 4500 biopsies (2007-2009) showed that OLGIM staging is less sensitive than OLGA staging in the identification of patients at high risk of gastric cancer (Rugge et al, 2011). However, replacement of atrophic gastritis by intestinal metaplasia in the staging of gastritis considerably increases inter-observer agreement. The correlation with the severity of gastritis remains at least as strong. Therefore, the OLGIM may be preferred over the OLGA for the prediction of gastric cancer risk in patients with premalignant lesions (Capelle et al, 2010).

Even though above precursor lesions were commonly known and found in everyday practice, there were no international recommendation to guide the clinicians in management of patients with such lesions. This resulted wide heterogeneity of surveillance practice and failure in diagnosing patients with early, curable stage cancer. The European Society of Gastrointestinal Endoscopy (ESGE), the European Helicobacter Study Group (EHSG), the European Society of Pathology (ESP) and the Sociedade Portuguesa de Endoscopia Digesti- 
va (SPED) have therefore combined efforts to develop evidence-based guideline on the management of patients with precancerous conditions and lesions in stomach (termed MAPS). Panel of European gastroenterologist pathologist and other researchers met in Barcelona, Spain in 2010, agreed on methodology, set up key questions for literature search and drafted preliminary statements. The panel divided into several subgroups searched for evidence on a certain question. Finally representatives of European national societies reviewed the evidence gathered and formed statements. Later, online sessions were held for voting and further comments; finally a second meeting held in Porto, Portugal finalized the guideline. The guideline details diagnostic assessment, treatment and follow-up of individuals with atrophic gastritis or intestinal metaplasia or dysplasia of gastric mucosa (Dinis-Ribeiro et al, 2012) (see Fig. 3).

\begin{tabular}{|c|c|c|c|c|}
\hline \multirow[b]{2}{*}{ Atrophy score } & \multicolumn{4}{|c|}{ Corpus } \\
\hline & $\begin{array}{l}\text { No atrophy } \\
\text { (score 0) }\end{array}$ & $\begin{array}{l}\text { Mild atrophy } \\
\text { (score 1) }\end{array}$ & $\begin{array}{l}\text { Moderate atrophy } \\
\text { (score 2) }\end{array}$ & $\begin{array}{l}\text { Severe atrophy } \\
\text { (score 3) }\end{array}$ \\
\hline \begin{tabular}{|c|}
$\begin{array}{c}\text { No atrophy (score 0) } \\
\text { (including incisura angularis) }\end{array}$ \\
\end{tabular} & Stage 0 & Stage I & Stage II & Stage II \\
\hline $\begin{array}{c}\text { Mild atrophy (score 1) } \\
\text { (including incisura angularis) }\end{array}$ & Stage I & Stage I & Stage II & Stage III \\
\hline \begin{tabular}{|l|}
$\begin{array}{l}\text { Moderate atrophy (score 2) } \\
\text { (including incisura angularis) }\end{array}$ \\
\end{tabular} & Stage II & Stage II & Stage III & Stage IV \\
\hline $\begin{array}{c}\text { Severe atrophy (score 3) } \\
\text { (including incisura angularis) }\end{array}$ & Stage III & Stage III & Stage IV & Stage IV \\
\hline
\end{tabular}

Figure 2. Gastritis Staging by OLGA system (Rugge \& Genta, 2005a, 2005b, 2007), published in Gut in 2007. Atrophy is score in a four-tiered scale (0-3) in each compartment. The atrophy stage defined from the combination of atrophic changes assessed in gastric antral and corporal biopsies.

The recommendations contain that conventional white light endoscopy cannot accurately differentiate between and diagnose pre-neoplastic gastric conditions/lesions. Thus, magnification chromoendoscopy or narrow-band imaging (NBI) endoscopy with or without magnification may be offered in these cases as it improves diagnosis of such lesions. In addition, at least four biopsies of the proximal and distal stomach, on the lesser and greater curvature, are needed for adequate assessment of premalignant gastric conditions. Systems for histopathological staging (e.g. OLGA or OLGIM assessment) may be useful for identifying subgroups of patients with different risks of progression to gastric cancer namely those with extensive lesions (i. e., atrophy and/or intestinal metaplasia in both antrum and corpus). Although only low potential applicability was reported by participants for this indicator, low serum pepsinogen levels can also predict this phenotype and, in such patients, H. pylori serology may also be useful for further detection of high risk individuals. Beyond a family history of gastric cancer, neither age, gender, H. pylori virulence factors, or host genetic variations change these clinical recommendations. Patients with extensive atrophy and/or extensive intestinal metaplasia should be offered endoscopic surveillance every 3 years. Patients with mild to moderate atrophy/intestinal metaplasia only in antrum do not need fol- 
low-up. If $H$. pylori infection is present, eradication should be offered to prevent high grade dysplasia or carcinoma. Patients with dysplasia without a visible endoscopic lesion should be closely followed up, either immediately and 6 to 12 months thereafter, or within 12 months, respectively, for those with high grade or low grade dysplasia. Those with dysplasia or cancer within an endoscopically visible lesion should undergo staging and resection (see Fig. 3.) (Dinis-Ribeiro et al, 2012).

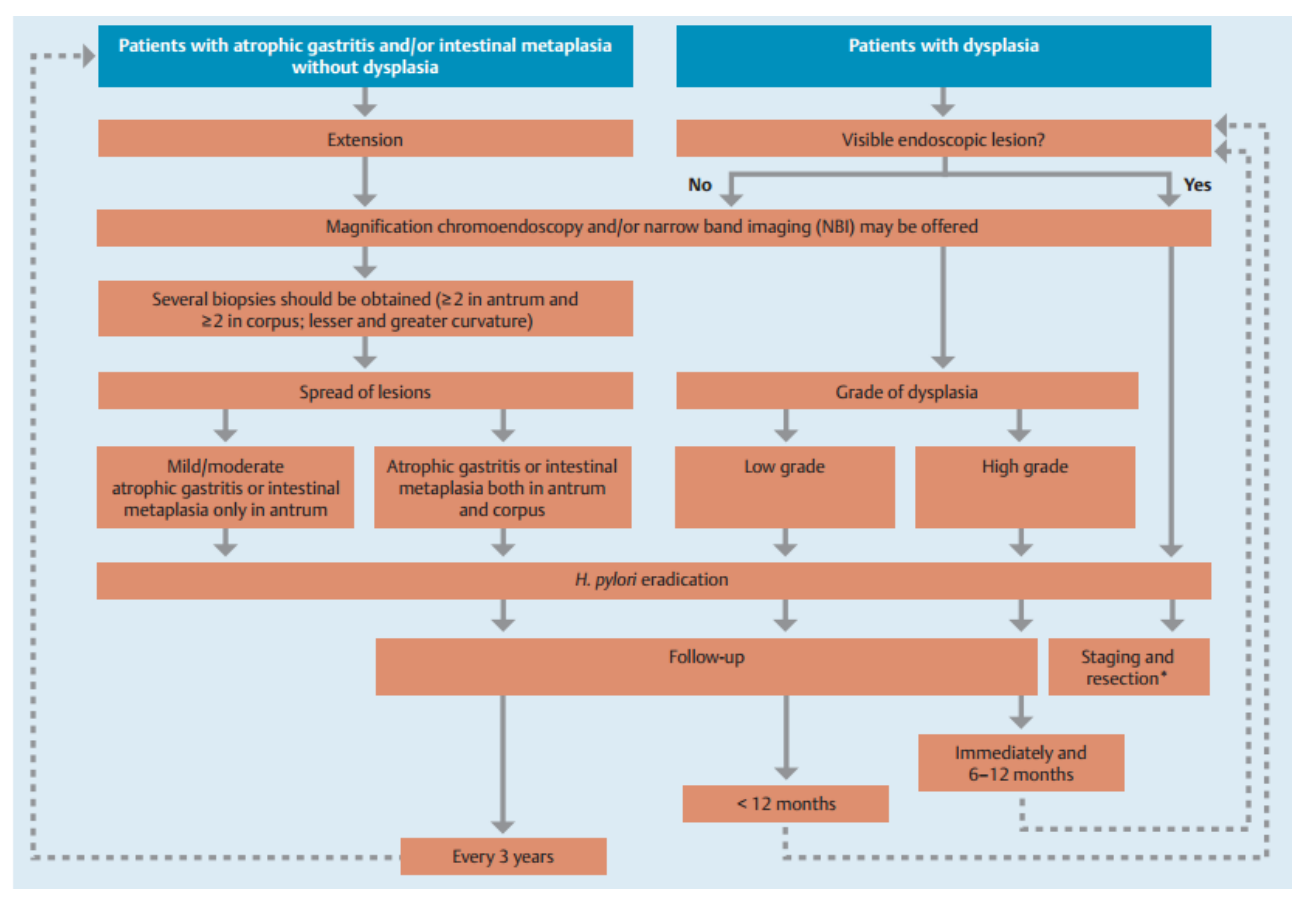

Figure 3. Summary of management for patients with atrophic gastritis, gastric intestinal metaplasia and gastric epithelial dysplasia. Published in Endoscopy, 2012 (Dinis-Ribeiro et al, 2012).

This review critically offers and emphasizes the necessity of an international consensus meeting, which will establish a more uniform classification of gastritis respecting the wider multidisciplinary aspects (morphology, clinical picture, endoscopic view, immunology, bacteriology, molecular pharmacology, general medicine, oncology and causative factors as well as social/environmental circumstances of the people) in this field.

\section{Conclusion}

During the about last 150 years the knowledge on "gastritides" has enlarged enormously. The discovered new forms of gastritis, the new etiopathogenic evidences have continuously 
modified our views on gastritis classification. Recently, good agreement has been established among pathologist and clinicians to standardise the methodology of biopsy sampling, histological assessment and reporting leading to reproducible and clinically useful diagnosis. Recent recommendations for the management of bleeding, H. pylori infected or cancer risk patients help clinicians to endorse up-to-date therapy and follow-up. Presently there are still many unanswered questions regarding lot of segment of various forms of gastritis. Pathologist still need to issue descriptive histological report of 'chronic non-specific gastritis' to clinicians due to either lack of clinical information or knowledge of identifying gastric inflammations distinctive from known categories. For reducing the number of these cases further communication and consensus (as well as further consensus meetings) will be needed between pathologists and gastroenterologists. The growing information from research and clinical studies might show further new directions and require modification of classification. It is possible that at some day the presently known different types of gastritis will be known as various stages of the same disease, or partition of a present form could happen due to discovered futural diverse etiologic causes.

\section{Author details}

Imre Laszlo Szabo, Kata Cseko, Jozsef Czimmer and Gyula Mozsik

First Department of Medicine, University of Pécs, Hungary

\section{References}

[1] Appelman H.D. (1994). Gastritis: terminology, etiology, and clinicopathological correlations: another biased view. Hum Pathol, Vol.25, pp.1006-19.

[2] Brinton W. (1857). On the Pathology, Symptoms and Treatment of Ulcer of the Stomach, London, J. Churchill.

[3] Bock O.A. (1974). The relationship between chronic gastritis, gastric ulceration and carcinoma of the stomach. A historical review. S Afr Med J, Vol.48: pp.2063-6.

[4] Capelle L.G., de Vries A.C., Haringsma J., et al. (2010). The staging of gastritis with the OLGA system by using intestinal metaplasia as an accurate alternative for atrophic gastritis. Gastrointest Endosc, Vol.71: pp.1150-8.

[5] Cheli R., Dodero M. (1956). Sulle alterazioni ghiandolari fundiche nelle gastriti croniche. Ricerche bioetiche e correlazioni anatomo-secretorie. Min Gastroenterol, Vol.4: pp.1-6.

[6] Correa P. (1980). The epidemiology and pathogenesis of chronic gastritis; three etiologic entities. Front Gastrointestinal Res, Vol. 6: pp.98-108. 
[7] Correa P. (1988). Chronic gastritis: a clinico-pathological classification. Am J Gastroenterol, Vol.83: pp.504-9.

[8] Correa P., Yardley J.H. (1992). Grading and classification of chronic gastritis: one American response to the Sydney System. Gastroenterology, Vol.102, pp.355-9.

[9] Crawford Q., Crawford A. (1832). Ulceration of the Brain. The Medico-Chirurgical Review, and Journal of Practical Medicine, Vol.16, pp.601.

[10] Dinis-Ribeiro M., Areia M., de Vries A.C., et. al. (2012). European Society of Gastrointestinal Endoscopy; European Helicobacter Study Group; European Society of Pathology; Sociedade Portuguesa de Endoscopia Digestiva. Management of precancerous conditions and lesions in the stomach (MAPS): guideline from the European Society of Gastrointestinal Endoscopy (ESGE), European Helicobacter Study Group (EHSG), European Society of Pathology (ESP), and the Sociedade Portuguesa de Endoscopia Digestiva (SPED). Endoscopy, Vol.44: pp.74-94.

[11] Dixon M.F. (1990). Progress in the pathology of gastritis and duodentitis. In: Gastrointestinal Pathology, Williams G.T. (Ed.), Springer-Verlag, Berlin, Germany, pp.1-27.

[12] Dixon M.F., Genta R.M., Yardley J.H., Correa P, Participants on the International Workshop on the Histopathology of Gastritis. (1996). Classification and grading of gastritis. The updated Sydney System. Am J Surg Pathol, Vol.20, pp.1161-81.

[13] Dixon M.F., Genta R.M., Yardley J.H., Correa P. (1997). Histological classification of gastritis and Helicobacter pylori infection: an agreement at last? The International Workshop on the Histopathology of Gastritis. Helicobacter, Vol.2 Suppl 1: pp.17-24.

[14] El-Zimaity H.M., Graham D.Y., al-Assi M.T., et al. (1996). Interobserver variation in the histopathological assessment of Helicobacter pylori gastritis. Hum Pathol, Vol.27: pp.35-41.

[15] El-Zimaity H. (2008). Gastritis and gastric atrophy. Curr Opin Gastroenterol, Vol.24: pp.682-6.

[16] Fenwick S. (1870). On atrophy of the stomach. Lancet, Vol. ii: pp.78-80.

[17] Genta R.M. (1996). Recognizing atrophy: another step toward a classification of gastritis. Am J Pathol, Vol.20 Suppl 1: pp.23-30.

[18] Glass G.B.J., Pitchumoni C.S. (1975). Atrophic gastritis. Hum Pathol, Vol.6: pp.219-50.

[19] Graham DY, Nurgalieva ZZ, El-Zimaity HM, et al.. (2006). Noninvasive versus histologic detection of gastric atrophy in a Hispanic population in North America. Clin Gastroenterol Hepatol, Vol.4: pp.306-14.

[20] Haot J., Hamichi L., Wallez L., Mainguet P. (1988). Lymphocytic gastritis: a newly described entity: a retrospective endoscopic and histological study. Gut, Vol.29: pp. 1258-64. 
[21] Haot J., Jouret A., Willette M., Gossuin A., Mainguet P. (1990). Lymphocytic gastritis--prospective study of its relationship with varioliform gastritis. Gut, Vol.31: pp. 282-5.

[22] Kozlowski W., Jochymski C, Markiewicz T. (2011). Chronic gastritis, In: Gastritis and Gastric Cancer - New Insights in Gastroprotection, Diagnosis and Treatments, Tonino P. (Ed.), 76-92, In-Tech, Rijeka, Croatia.

[23] Marshall B.J., Warren J.R. (1984). Unidentified curved bacilli in the stomach of patients with gastritis and peptic ulceration. Lancet, Vol.1: pp.1311-5.

[24] Meining A., Riedl B., Stolte M. (2002). Features of gastritis predisposing to gastric adenoma and early gastric cancer. J Clin Pathol, Vol.55: pp.770-3.

[25] Misiewicz J.J., Tytgat G.N.J., Goodwin C.S., et al. (1990). The Sydney System: a new classification of gastritis. World Congresses of Gastroenterology, 1990 August 26-31. Sydney, pp.1-10.

[26] Morson B.C., Sobin L.H., Grundmann E., Johansen A., Nagayo T., Serck-Hanssen A. (1980). Precancerous conditions and epithelial dysplasia in the stomach. J Clin Pathol, Vol.33: pp.711-21.

[27] Offerhaus GJ, Price AB, Haot J, et al. (1999). Observer agreement on the grading of gastric atrophy. Histopathology, Vol.34: pp.320-5.

[28] Owen D.A: (1989). Stomach. In: Diagnostic surgical Pathology and Its Clinical Implications, Stenberg S.S. (Ed.), New York, NY, Raven Press, pp. 939-48.

[29] Palmer E.D. (1956). Clinical benmefit of routine combined oesophagogastroscopy with the help of the two trabnsoesophagoscopic gastroscope. Bull Am Gastrosc Soc, Vol.4: pp.7-11.

[30] Price A.B., Misiewicz J.J. (1991). Sydney classification for gastritis. Lancet, Vol.337:pp. 174.

[31] Price A.B. (1991). The Sydney System: Histological division. J Gastoenterol Hepatol, Vol.6, pp.209-22.

[32] Rugge M., Di Mario F., Cassaro M., et al. (1993). Pathology of the gastric antrum and body associated with Helicobacter pylori infection in non-ulcerous patients: is the bacterium a promoter of intestinal metaplasia? Histopathology, Vol.22: pp.9-15.

[33] Rugge M., Farinati F., Baffa R., Sonego F., Di Mario F., Leandro G., Valiante F. (1994). Gastric epithelial dysplasia in the natural history of gastric cancer: a multicenter prospective follow-up study. Interdisciplinary Group on Gastric Epithelial Dysplasia. Gastroenterology, Vol.107: pp.1288-96.

[34] Rugge M., Cassaro M., Farinati F., Di Mario F. (1997). Diagnosis of gastric carcinoma in Japan and western countries. Lancet, Vol.350: pp.448. 
[35] Rugge M., Correa P., Dixon M.F., et al. (2000). Gastric dysplasia: the Padova international classification. Am J Surg Pathol, Vol.24: pp.167-76.

[36] Rugge M., Russo V.M., Guido M. (2003). Review article: what have we learnt from gastric biopsy? Aliment Pharmacol Ther, Vol.17 Suppl 2: pp.68-74.

[37] Rugge M., Genta R.M. (2005a). Staging and grading of chronic gastritis. Hum Pathol, Vol.36: pp.228-33.

[38] Rugge M., Genta R.M., OLGA Group. (2005b). Staging gastritis: an international proposal. Gastroenterology, Vol.129: pp.1807-8.

[39] Rugge M., Meggio A., Pennelli G., et al. (2007). Gastritis staging in clinical practice: the OLGA staging system. Gut,Vol.56: pp.631-6.

[40] Rugge M., de Boni M., Pennelli G., et al. (2010). Gastritis OLGA-staging and gastric cancer risk: a twelve-year clinico-pathological follow-up study. Aliment Pharmacol Ther, Vol.31: pp.1104-11.

[41] Rugge M., Fassan M., Pizzi M., et al. (2011). Operative link for gastritis assessment vs operative link on intestinal metaplasia assessment. World J Gastroenterol, Vol.17: pp. 4596-601.

[42] Schindler R. (1947). Gastritis. London: William Heinmann (Medical Books).

[43] Sipponen P., Kekki M., Haapakoski J., Ihamäki T., Siurala M. (1985). Gastric cancer risk in chronic atrophic gastritis: statistical calculations of cross-sectional data. Int J Cancer, Vol.35: pp.173-7.

[44] Sipponen P, Price A.B. (2011). The Sydney System for classification of gastritis 20 years ago. J Gastroenterol Hepatol, Vol.26 Suppl 1: pp.31-4.

[45] Sipponen P., Riihelä M., Hyvärinen H., Seppälä K. (1994). Chronic nonatropic ('superficial') gastritis increases the risk of gastric carcinoma. A case-control study. Scand J Gastroenterol, Vol.29: pp.336-40.

[46] Sipponen P., Stolte M. (1997). Clinical impact of routine biopsies of the gastric antrum and body. Endoscopy, Vol.29: pp.671-8.

[47] Sobala G.M., King R.F., Axon A.T., Dixon M.F. (1990). Reflux gastritis in the intact stomach. J Clin Pathol, Vol.43: pp.303-6.

[48] Stolte M., Meining A. (2000). Helicobacter pylori gastritis of the gastric carcinoma phenotype: is histology capable of identifying high-risk gastritis? J Gastroenterol, Vol.35 Suppl 12: pp.98-101.

[49] Stolte M., Meining A. (2001). The updated Sydney system: classification and grading of gastritis as the basis of diagnosis and treatment. Can J Gastroenterol, Vol.15: pp. 591-8.

[50] Strickland R.G., Mackay I.R. (1973). A reappraisal of the nature and significance of chronic atrophic gastritis. Am J Dig Dis, Vol.18: pp.426-40. 
[51] Szabo I., Illes A., Godi S., et al. (2012). Gastritis staging in clinical practice by OLGA (Operative Link for Gastritis Assessment) system - Evaluation of gastric mucosal atrophy and metaplasia. Z Gastroenterol, Vol.50, A72.

[52] Vaughan W. (1945). Antral Gastritis: Roentgenologic and Gastroscopic Findings. Radiology, Vol.44, pp. 531-42.

[53] Warren J.R., Marshall B. (1983). Unidentified curved bacilli on gastric epithelium in active chronic gastritis. Lancet, Vol.321, pp.1273-4.

[54] Warren S., Meissner W.A. (1944). Chronic Gastritis and Carcinoma of the Stomach. Gastroenterology, Vol.3: pp.251-6.

[55] Whitehead R., Truelove S.C., Gear M.W. (1972). The histological diagnosis of chronic gastritis in fibreoptic gastroscope biopsy specimens. J Clin Pathol, Vol.25: pp.1-11.

[56] Wood I.J., Doig R.K., Motteram R. et al. (1949). Gastric biopsy; report on 55 biopsies using a new flexible gastric biopsy tube. Lancet, Vol.1: pp.18-21.

[57] Wyatt J.I., Dixon M.F. (1988). Chronic gastritis--a pathogenetic approach. J Pathol, Vol.154: pp.113-24.

[58] Yadley J.H. (1990). Pathology of chronic gastritis and duodenitis. In: Gastrointestinal Pathology, Ch: 3, Goldman H., Appelman H.D., Kaufman N. (Eds.), Williams \& Wilkins, Baltimore, MD, pp.69-121. 
